\title{
Tools for uncertainty calculations in force measurement
}

\author{
Dirk Röske ${ }^{1}$, Jussi Ala-Hiiro ${ }^{2}$, Andy Knott ${ }^{3}$, Nieves Medina ${ }^{4}$, Petr Kaspar ${ }^{5}$, Mikołaj Woźniak ${ }^{6}$ \\ ${ }^{1}$ Physikalisch-Technische Bundesanstalt, Bundesallee 100, 38116 Braunschweig, Germany \\ ${ }^{2}$ VTT MIKES Metrology, Tehdaskatu 15, Puristamo 9P19 87100 Kajaani, Finland \\ ${ }^{3}$ National Physical Laboratory, Hampton Rd, Teddington, Middlesex TW11 OLW, United Kingdom \\ ${ }^{4}$ Centro Español de Metrología, Calle del Alfar, 2, 28760 Tres Cantos, Madrid, Spain \\ ${ }^{5}$ Cesky Metrologicky Institut, Okružní 31, 63800 Brno, Czech Republic \\ ${ }^{6}$ Ministerstwo Gospodarki, Główny Urzq̨d Miar, ul. Elektoralna 2, 00-139 Warszawa, Poland
}

\begin{abstract}
Within the framework of the European Metrology Research Programme (EMRP), tools for the calculation of measurement uncertainties have been developed. The Joint Research Project (JRP) 63 of the "SI Broader Scope II" (SIB) call of the EMRP is entitled: "Force traceability within the meganewton range". The project was started in July 2013 and had a duration of 36 months. The aim of the SIB63 project was to improve the traceability of the force measurement especially in the meganewton range. This paper presents the results of work package 4 "Improved dissemination of the SI unit of force". The tools developed by the partners are available from the website of the project.
\end{abstract}

Section: RESEARCH PAPER

Keywords: EMRP SIB 63; uncertainty; force measurement; calculation tools

Citation: Dirk Röske, Jussi Ala-Hiiro, Andy Knott, Nieves Medina, Petr Kaspar, Mikołaj Woźniak, Tools for uncertainty calculations in force measurement, Acta IMEKO, vol. 6, no. 1, article 9, April 2017, identifier: IMEKO-ACTA-06 (2017)-01-09

Section Editor: Paul Regtien, The Netherlands

Received September 9, 2016; In final form February 13, 2017; Published April 2017

Copyright: (C) 2017 IMEKO. This is an open-access article distributed under the terms of the Creative Commons Attribution 3.0 License, which permits unrestricted use, distribution, and reproduction in any medium, provided the original author and source are credited

Funding: The research leading to these results has received funding from the European Union on the basis of Decision No $912 / 2009 / E C$. The EMRP is jointly funded by the EMRP participating countries within EURAMET and the European Union

Corresponding author: Dirk Röske, e-mail: dirk.roeske@ptb.de

\section{INTRODUCTION}

The main objective of the research project "Force traceability within the meganewton range" (SIB63) in the European Metrology Research Programme (EMRP) was to improve the traceability of force measurement from primary standards to calibration services and testing laboratories especially in the meganewton range. The project was started in July 2013 and had a duration of 36 months.

The aim of the project was to develop new methods that could be applied by users of measurement devices for large forces in industrial calibration laboratories and applications as well as in testing laboratories. Different work packages (WP) had been defined dealing with build-up systems of force transducers and extrapolation methods of measurement results (WP1), with multi-component measurements (WP2) and with time-dependent effects like creep and hysteresis (WP3).

The present paper describes the work that was undertaken within work package 4 Improved dissemination of the SI unit of force
(WP4) during the project's lifetime.

The key idea of WP4 was to improve traceability by taking various influencing effects into account. This is done by applying corrections to the measurement results based on mathematical models and known parameter values. For the corrected results, measurement uncertainties can be calculated using the tools provided to the users from the project's website.

The procedure of WP4 was as follows. First, the application conditions and requirements for the calibration depending on the further use of the force measuring instrument were compiled based on an on-line questionnaire. Second, the corresponding technical parameters and coefficients describing the effects of application conditions on the measurement result were collected or defined. Third, for nine of the parameters and coefficients, detailed models and elaborated uncertainty calculation examples were provided. They are publicly available from the website [1]. Fourth, for at least six of the models, online calculations tools were developed. For offline use, a 
spreadsheet file, including the same models, was programmed and is also publicly available from the website of the project.

\section{APPLICATION CONDITIONS}

Force transducers are often calibrated under laboratory conditions. In the later use of these instruments the application conditions must be taken into account if they differ from the calibration conditions to an extent that affects the measurement result. In order to receive feedback from the stakeholders about their application conditions, an online form was generated (Figure 1). It is still publicly available from the web address http://www.ptb.de/emrp/forcemetrology.html [1]. All graphics are screenshots taken from the project's website. If the figures are difficult to read, please open - if available - the website.

As the next step, a survey was undertaken and 66 stakeholders were asked to take part by submitting the filled-in form to the project team. 24 users replied and all the data received was entered into the database and can be found under "Work Packages/WP4.1 Application conditions" on the website.

The intention of the survey was to find out under which conditions and in what ranges (for example, temperatures up to $1100{ }^{\circ} \mathrm{C}$ ) force transducers are sometimes used. It was not intended to develop methods covering all these ranges so users should be aware that, for example, a temperature coefficient that was measured in the range up to $30{ }^{\circ} \mathrm{C}$ may not be useful in the range of $100{ }^{\circ} \mathrm{C}$ or above.

\section{TECHNICAL PARAMETERS AND COEFFICIENTS}

Several parameters or coefficients are already defined in written standards, for example in [2], or in scientific papers. The available information was compiled into one list together with references under "Work Packages/WP4.2 Parameters and coefficients" on the website (Figure 2). All parameters are given with their name, symbol and unit, as well as a description. In some cases, it was necessary to adapt the definition given in the

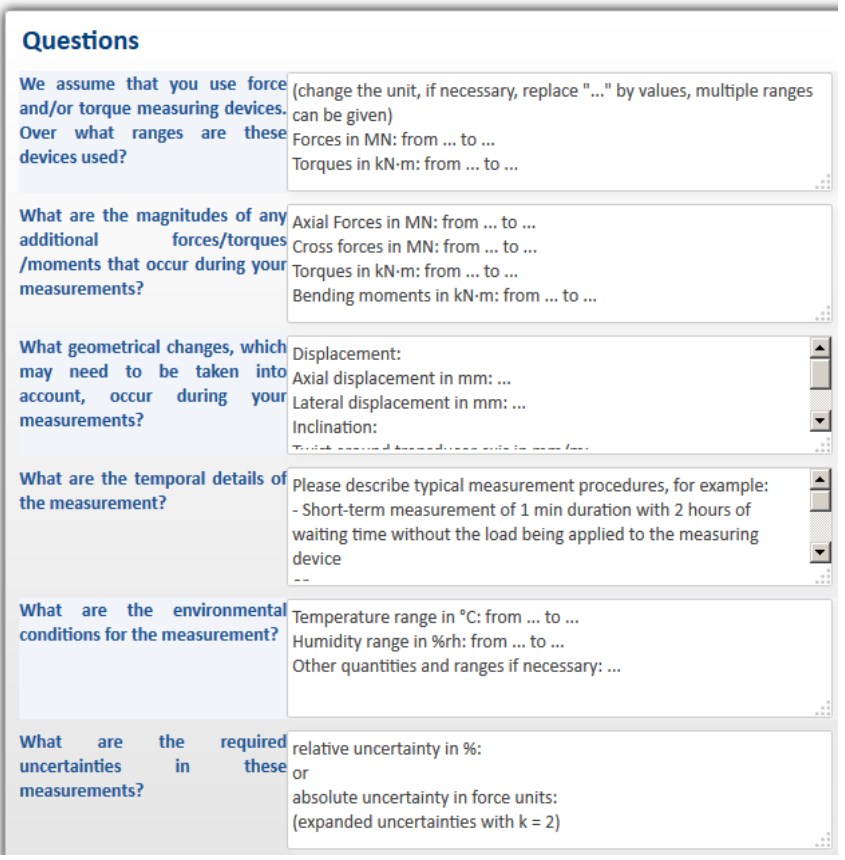

Figure 1. Questions from the on-line questionnaire about application conditions.
Part 1 - Parameter and coefficient definitions

Geometrical

\begin{tabular}{|l|l|l|}
\hline Parameter & $\begin{array}{l}\text { Symbol } \\
\text { and Unit }\end{array}$ & \multicolumn{1}{c|}{ Description } \\
\hline Eccentricity effect & $\begin{array}{l}\mathrm{O}_{\mathrm{C}, \mathrm{E}} \\
\text { in } \\
\mathrm{IU} / \mathrm{mm}\end{array}$ & $\begin{array}{l}\text { Output signal of the force transducer at rated force due to a defined } \\
\text { displacement of the force action line parallel to the measurement axis. } \\
\text { The greatest eccentricity effect in the plane vertical to the measurement } \\
\text { axis is to be stated. }\end{array}$ \\
\hline $\begin{array}{l}\text { Geometrical effects } \\
\text { in } \\
\text { systems }\end{array}$ & suild-up & see Mechanical effects in build-up systems \\
\hline
\end{tabular}

\begin{tabular}{|c|c|c|}
\hline \multicolumn{3}{|l|}{ Mechanical } \\
\hline Parameter & $\begin{array}{c}\text { Symbol } \\
\text { and Unit }\end{array}$ & Description \\
\hline Torque effect & $\begin{array}{l}D_{\mathrm{C}, \mathrm{MT}} \\
\text { in } \\
\text { IU } \\
(\mathrm{N} \cdot \mathrm{m})\end{array}$ & $\begin{array}{l}\text { Deviation of the output signal of the force transducer due to a torque } \\
\text { around the measurement axis. The torque is to be stated. }\end{array}$ \\
\hline $\begin{array}{l}\text { Lateral force } \\
\text { effect }\end{array}$ & $\begin{array}{l}D_{\mathrm{C}, \mathrm{FL}} \\
\text { in } \\
\text { IU / N }\end{array}$ & $\begin{array}{l}\text { Deviation of the output signal of the force transducer due to a lateral } \\
\text { force. The lateral force shall be applied perpendicular to the } \\
\text { measurement axis in the point of force introduction. The greatest } \\
\text { lateral force effect and its direction is to be stated. }\end{array}$ \\
\hline $\begin{array}{l}\text { Bending moment } \\
\text { effect }\end{array}$ & $\begin{array}{l}D_{C, M B} \\
\text { in } \\
\text { IU } \\
(\mathrm{N} \cdot \mathrm{m})\end{array}$ & $\begin{array}{l}\text { Deviation of the output signal of the force transducer due to a bending } \\
\text { moment. The bending moment shall be applied around an axis } \\
\text { perpendicular to the measurement axis. The greatest bending moment } \\
\text { effect and its direction is to be stated. }\end{array}$ \\
\hline $\begin{array}{l}\text { Mechanical } \\
\text { effects in bulld-up } \\
\text { systems }\end{array}$ & $\begin{array}{l}d L \\
\text { in } \\
\%\end{array}$ & $\begin{array}{l}\text { Relative deviation of the sum of the forces indicated by the single } \\
\text { transducers from the introduced calibration force }\end{array}$ \\
\hline $\begin{array}{l}\text { Multi-component } \\
\text { effects }\end{array}$ & & to be delivered by WP2 \\
\hline
\end{tabular}

Figure 2. Parameter and coefficient definitions (part of the table).

guidelines for a better uniformity. This may also serve as a proposal for a future revision of the guidelines.

The parameters and coefficients were grouped into Geometrical, Mechanical, Temporal, Electrical and Environmental effects.

For some of the parameters, exact values are given as well. Unfortunately, this list is very short and it does not cover most of the parameters due to a lack of corresponding measurement results. If a user needs to know the exact value of a parameter, then it might be necessary to carry out corresponding measurements. On the other hand, depending on the target uncertainty, it may be sufficient to work with parameter ranges in the form of upper limits of their absolute values from data sheets. For example, the temperature effect on the characteristic value ("sensitivity") of a C4 force transducer from HBM [3] is not higher than $0.01 \%$ per $10 \mathrm{~K}$ temperature change (see Figure 3).

\begin{tabular}{|c|c|c|}
\hline \multicolumn{3}{|c|}{ Parameter ranges (upper limits of absolute value) from data sheets } \\
\hline Parameter & Symbol & Range \\
\hline $\begin{array}{l}\text { Temperature effect on } \\
\text { characteristic value per } 10 \mathrm{~K}\end{array}$ & $T K_{\mathrm{c}}$ & $\left|T K_{\mathrm{c}}\right|<0.01 \% /(10 \mathrm{~K})$ \\
\hline $\begin{array}{l}\text { Temperature effect on } \\
\text { zero signal per } 10 \mathrm{~K}\end{array}$ & $T K_{0}$ & $\left|T K_{0}\right|<0.015 \% /(10 \mathrm{~K})$ \\
\hline $\begin{array}{l}\text { Ambient pressure effect on } \\
\text { zero signal per } 1 \mathrm{kPa}\end{array}$ & $\rho K_{0}$ & $\left|\rho K_{0}\right|<0.015 \% /(1 \mathrm{kPa})$ \\
\hline Relative eccentricity effect & $d_{E, r}$ & $\left|d_{E, r}\right|<0.01 \% / \mathrm{mm}$ \\
\hline $\begin{array}{l}\text { Relative lateral force effect } \\
\text { (lateral force: } 10 \% \text { of } F_{\text {nom }} \text { ) }\end{array}$ & $d_{Q, r}$ & $\left|d_{Q, r}\right|<0.03 \% /\left(0.1 \cdot F_{\text {nom }}\right)$ \\
\hline $\begin{array}{l}\text { Excitation voltage effect on } \\
\text { characteristic value }\end{array}$ & $d_{\mathrm{C}, \mathrm{U}}$ & $\left|d_{\mathrm{C}, \mathrm{u}}\right|<0.1 \%$ in the excitation voltage range \\
\hline $\begin{array}{l}\text { Excitation voltage effect on } \\
\text { zero signal }\end{array}$ & $d_{\text {so,u }}$ & $\left|d_{s 0 . u}\right|<0.5 \%$ in the excitation voltage range \\
\hline $\begin{array}{l}\text { Temperature effect on } \\
\text { characteristic value per } 10 \mathrm{~K}\end{array}$ & $T K_{\mathrm{c}}$ & $\left|T K_{\mathrm{c}}\right|<0.01 \% /(10 \mathrm{~K})$ \\
\hline $\begin{array}{l}\text { Temperature effect on } \\
\text { zero signal per } 10 \mathrm{~K}\end{array}$ & $T K_{0}$ & $\left|T K_{0}\right|<0.015 \% /(10 \mathrm{~K})$ \\
\hline Relative eccentricity effect & $d_{E, r}$ & $\left|d_{E, r}\right|<0.005 \% / \mathrm{mm}$ \\
\hline $\begin{array}{l}\text { Relative lateral force effect } \\
\text { (lateral force: } 10 \% \text { of } F_{\text {nom }} \text { ) }\end{array}$ & $d_{\mathrm{Q}, \mathrm{r}}$ & $\left|d_{Q, r}\right|<0.03 \% /\left(0.1 \cdot F_{\text {nom }}\right)$ \\
\hline
\end{tabular}

Figure 3. Parameter ranges from data sheets. 


\section{DETAILED MODELS AND EXAMPLES}

\subsection{Models}

The uncertainty contributions were then evaluated for some of the parameters and their related influencing quantities. In [4] it was shown that the uncertainty calculation can be performed with quite simple software tools.

The various influencing effects are given under "Work Packages/WP4.3 Uncertainty contributions" on the website (Figure 4), arranged in categories. The intention is that the user applies corrections to the measurement results based on the knowledge of the effect, the mathematical model describing the influence and the values of the parameters including their uncertainties.

The models follow directly from the above given definitions of the parameters and coefficients. If new influencing quantities or effects other than those in the list of models have to be considered, the related models can be developed on the basis of the models on the page.

\subsection{Calculation examples}

For some of the influencing effects from the list in Figure 4, elaborated example calculations are given in the lower part of the WP4.3 page, see Figure 5.

These examples are organized using an accordion element in the graphical user interface of the page. It consists of a vertically stacked list of alternately expandable header items, meaning a maximum of one item can be expanded at a time.

Usually [5], for uncertainty calculations only linearized models are applied and the underlying formula is given in (1):

$u_{c}^{2}(y)=\sum_{i=1}^{N}\left(\frac{\partial f}{\partial x_{i}}\right)^{2} u^{2}\left(x_{i}\right)$.

In the case of our form, an enhanced formula (2) is used

$u_{c}^{2}(y)=\sum_{i=1}^{N}\left(\frac{\partial f}{\partial x_{i}}\right)^{2} u^{2}\left(x_{i}\right)+$

$+\sum_{i=1}^{N} \sum_{j=1}^{N}\left[\frac{1}{2}\left(\frac{\partial^{2} f}{\partial x_{i} \partial x_{j}}\right)^{2}+\frac{\partial f}{\partial x_{i}} \frac{\partial^{3} f}{\partial x_{i} \partial x_{j}^{2}}\right] u^{2}\left(x_{i}\right) u^{2}\left(x_{j}\right)$.

\begin{tabular}{|l|l|}
\hline WP4 Improved traceability \\
WP4 has four tasks. Here we publish the results of these tasks. \\
Task 4.3 - Determination of the uncertainty of measurement results \\
in the application of force transducers under real conditions \\
On this page we provide mathematical models with description and \\
numerical examples for the calculation of uncertainties.
\end{tabular}

Figure 4. List of categories and influencing effects.

\begin{tabular}{|c|}
\hline $\begin{array}{l}\text { Detailed models and elaborated examples } \\
\text { Terminology and abbreviations: } \\
\text { Indication - Value indicated by the measuring instrument, also: Output } \\
\text { Zero indication - Indication of the unloaded transducer } \\
\text { Deflection - Difference between the indication at acting load and the zero indication in mounted } \\
\text { state } \\
\text { Nominal force - Force the measuring instrument is designed for } \\
\text { Characteristic value - Deflection at nominal force } \\
\text { Sensitivity - Deflection to force ratio, also: Characteristic value to nominal force ratio (in } \\
(\mathrm{mV} / \mathrm{V}) / \mathrm{N}, \mathrm{Hz} / \mathrm{N}, \ldots) \\
\mathrm{IU}=\text { indicated unit, for example, } \mathrm{N}, \mathrm{mV} / \mathrm{V}, \mathrm{kHz}\end{array}$ \\
\hline , Eccentricity effect on characteristic value \\
\hline - Lateral force effect on characteristic value \\
\hline Storage effect on characteristic value \\
\hline Storage effect on zero signal \\
\hline Excitation voltage effect on characteristic value \\
\hline , Excitation voltage effect on zero signal \\
\hline Temperature effect on characteristic value \\
\hline Humidity effect on characteristic value \\
\hline Pressure effect on zero signal \\
\hline
\end{tabular}

Figure 5. Collection of detailed models and example calculations.

One of the advantages of this enhanced calculation method is that additional contributions to uncertainty are taken into account. If, for example, the user works at the same temperature as the calibration laboratory $\left(20^{\circ} \mathrm{C}\right.$, see above), the correction due to the temperature coefficient is zero, but due to a supposed higher uncertainty of the temperature measurement (for example, $0.5 \mathrm{~K}$ instead of $0.1 \mathrm{~K}$ ) the result should also have a higher uncertainty.

In the case of the example shown in Figure 6, the effect of temperature on the characteristic value is calculated when the transducer is used at $35^{\circ} \mathrm{C}$ after it was calibrated in an airconditioned laboratory at $20^{\circ} \mathrm{C}$. The standard uncertainty of measurement is $0.25 \%$. Due to the known temperature

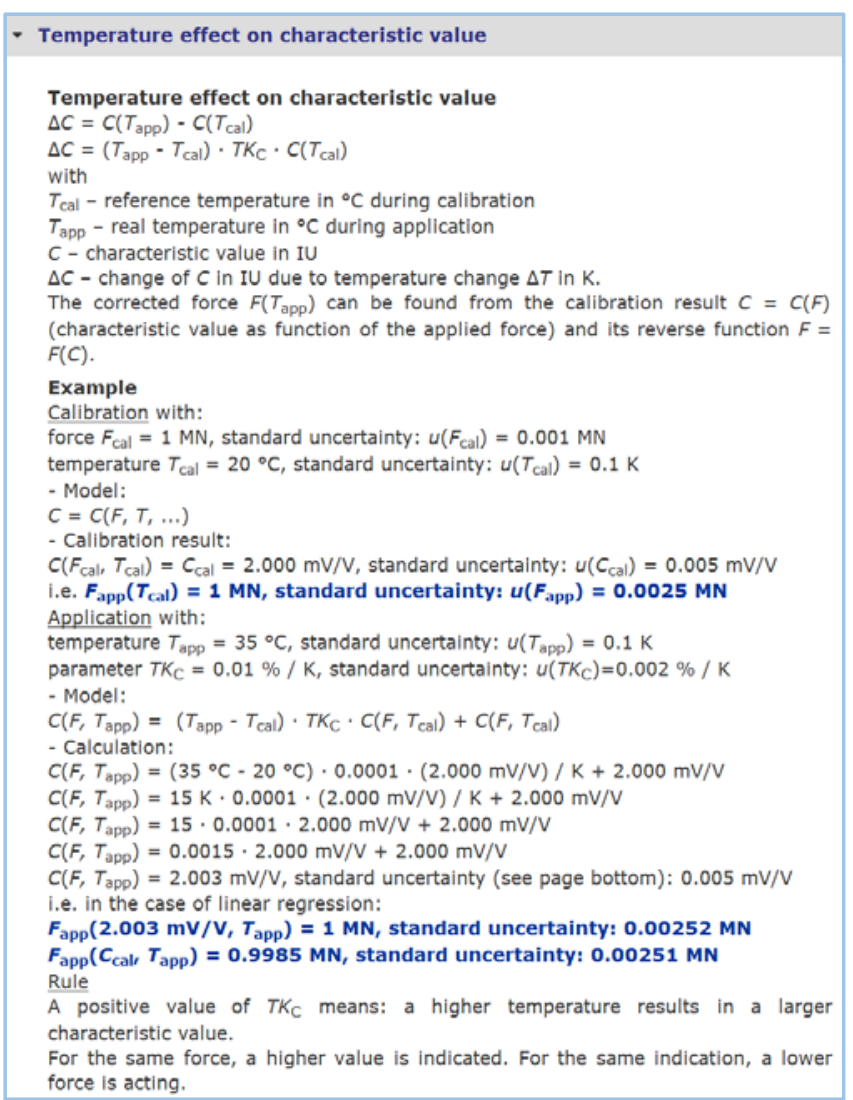

Figure 6. Example of a fully elaborated uncertainty calculation including a corrected result. 
coefficient of $0.01 \%$ per $10 \mathrm{~K}$, the characteristic values changed from $2.000 \mathrm{mV} / \mathrm{V}$ at $1 \mathrm{MN}$ to $2.003 \mathrm{mV} / \mathrm{V}$.

The uncorrected result has an additional error of $0.15 \%$. Depending on the application requirements, this can be either low enough to be ignored or it needs to be considered. If the effect is taken into account by applying a correction to the measurement result - which is the preferred way according to the GUM [5], the corrected value has an uncertainty of $0.252 \%$ which is slightly higher than the uncertainty of the calibration result $(0.25 \%)$. The increase is mainly caused by the uncertainty in the knowledge of the temperature coefficient $T_{\mathrm{KC}}$.

The example calculations are also used for the test of correctness and validation of the online and offline tools that are described in the following section.

\section{ONLINE AND OFFLINE CALCULATIONS TOOLS}

The developed online tools can be found under "Work Packages/WP4.4 Software tool" on the website (Figure 7). The user should enter corresponding values into all white input text boxes of the form. After this is done, a click on the "Evaluation" button calculates the results and shows them in the grey text boxes together with a list of contributions and an explanation below the form (Figure 8).

The calculations are performed in the internet browser on the user's local computer. For this purpose, JavaScript must be supported by the browser and enabled. The use of this tool is free but without any warranty. The source code is accessible and can be checked.

The "Reset" button can be used to delete the current results; the values in the white boxes are not affected. This allows the user to obtain a form without any results but it is not necessary to use this reset function, as any input value can be changed at any time and, by pressing the "Evaluation" button, the results can be re-calculated using these new values. The user should be aware that the indicated results will not correspond to the input values if the latter have been changed without starting a recalculation using the "Evaluation" button.

The table below the form shows the contributing variances in descending order. In the example of Figure 8 it can be seen that the main contributions come from the uncertainty of the transducer calibration and the uncertainty of the temperature coefficient.

In addition to the online tools, an Excel file is available for offline use. The first sheet in this file contains a short

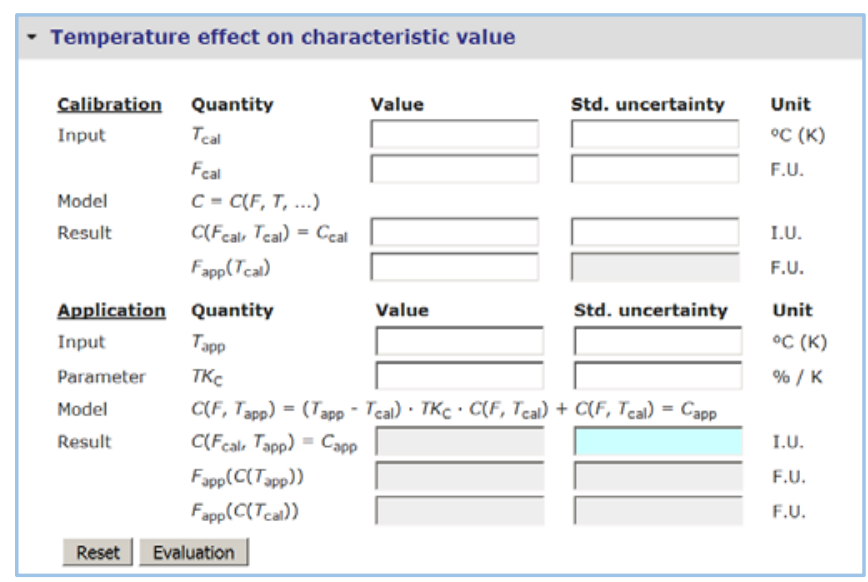

Figure 7. Example of an online tool form.

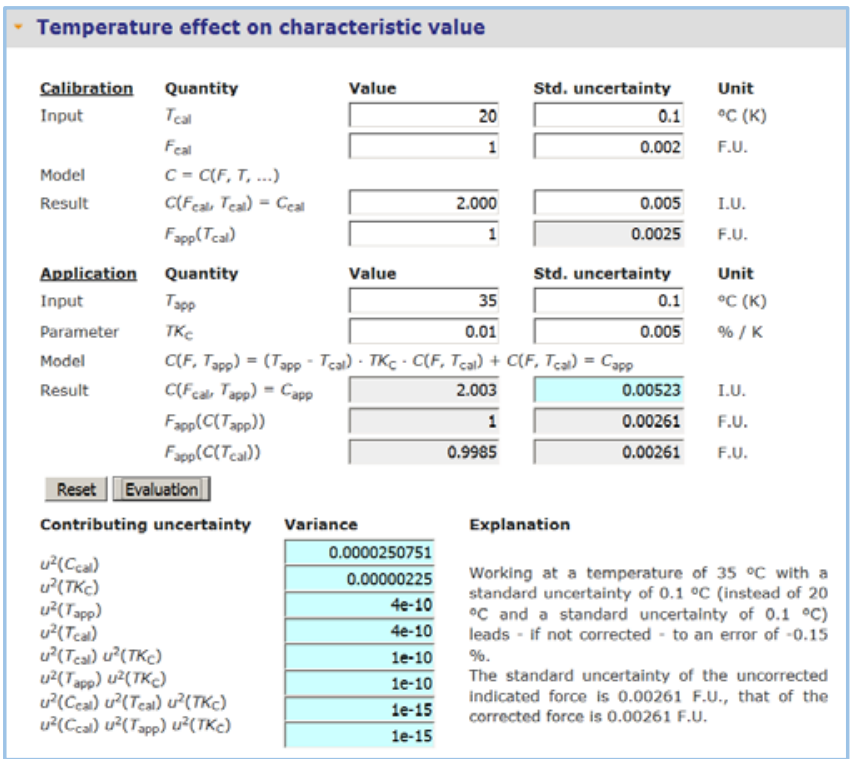

Figure 8. The filled-in form of Figure 7 with calculated results and explanation.

description together with internal links to the other sheets and some settings for the units in which the values are given. The second sheet offers some explanation of technical terms including their units. Each following sheet contains one model and its structure is similar to that on the website. The sheets contain the model and descriptions, input fields (cells) for data, results fields (cells) for the calculation results as well as the "Reset" and "Evaluation" buttons and the contributing variances, and the explanation.

The calculations in this spreadsheet file are based on macros. For the full functionality of the files macros must therefore be allowed. Depending on the settings of the local programme, the user may be asked to allow macros to be executed by the programme.

The last sheet of the file offers a graphical representation of the different contributing uncertainties (Figure 9).

The user can select which effects and influences should be

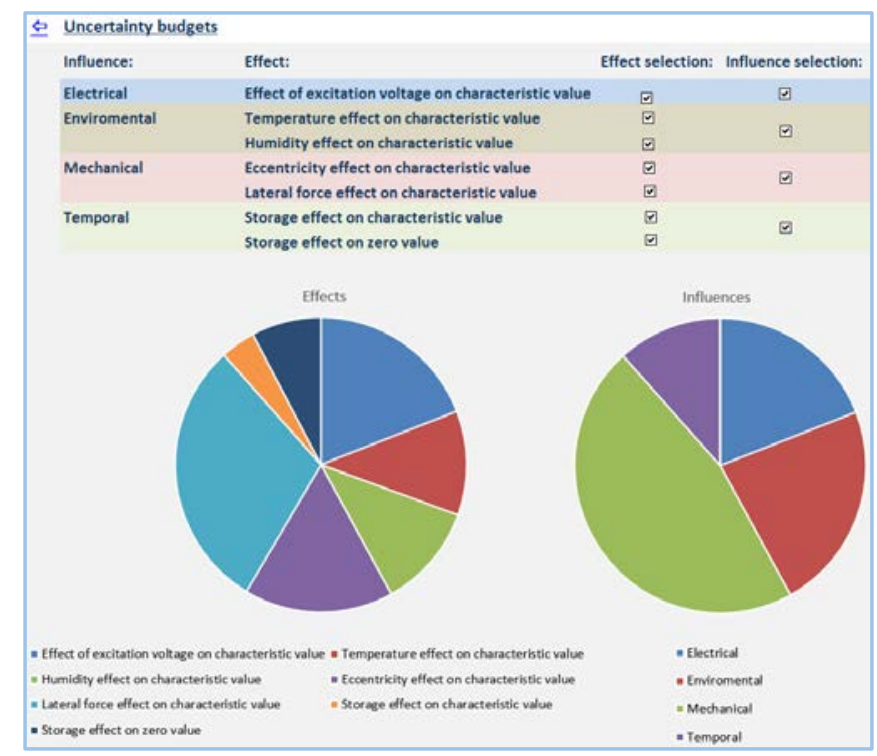

Figure 9. Pie charts of the contributing effects and influences (Source: Excel file [6]). 
taken into account by checking or unchecking the corresponding checkbox in the table above the charts. The graphics will be updated accordingly.

\section{CONCLUSIONS}

The methods and tools developed within this work package should help the users of calibrated force transducers to better estimate the measurement uncertainty with less effort, thus improving the traceability of force measurement. It should be noted that the methods and tools described in this paper are limited neither to the meganewton force measuring range nor indeed to the quantity force, so they can equally be applied to torque or pressure measurements.

\section{ACKNOWLEDGEMENT}

The research leading to these results has received funding from the European Union on the basis of Decision No 912/2009/EC. The EMRP is jointly funded by the EMRP participating countries within EURAMET and the European Union.

\section{REFERENCES}

[1] EMRP SIB63 "Force traceability in the meganewton range", [Online], http://www.ptb.de/emrp/sib63-home.html.

[2] VDI/VDE/DKD 2638 Kenngrößen für Kraftaufnehmer Begriffe, 2008-10, (German and English versions in one document), https://www.vdi.de/richtlinie/vdivdedkd 2638kenngroessen fuer kraftaufnehmer begriffe/.

[3] HBM C4 Force Standard Data Sheet, Special features, http://www.hbm.com.pl/pdf/b0663.pdf.

[4] D. Röske, "Uncertainty Calculations Using Free CAS Software Maxima," in IMEKO 22 $2^{\text {nd }}$ TC3, 12 $2^{\text {th }}$ TC5 and $3^{\text {rd }}$ TC22 International Conferences, Cape Town, South Africa, February 2014, http://www.imeko.org/publications/tc3-2014/IMEKOTC3-2014-016.pdf.

[5] BIPM JCGM 100:2008, Evaluation of measurement data - Guide to the expression of uncertainty in measurement, http://www.bipm.org/utils/common/documents/jcgm/JCGM 1002008 E.pdf.

[6] Excel file for offline calculation of measurement uncertainties, http://www.ptb.de/emrp/fileadmin/documents/forcemetrology /WorkPackages/WP4/uploads/WP4.4 Spreadsheet tool_v1.0.1 .xlsm.

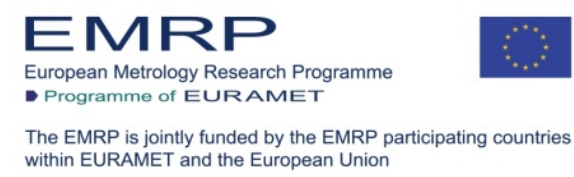

